\title{
Wound Closure on the Neonatal Rat Skin I. The Modulation of the Thickness of Epidermis at the Closing Incisional Wounds
}

\author{
Mary Arai, Takashi Matsuzaki, Setsunosuke Ihara* \\ Department of Biological Science, Faculty of Life and Environmental Science, Shimane University, Matsue, Japan \\ Email: *ihara@life.shimane-u.ac.jp
}

Received September 24, 2013; revised October 24, 2013; accepted November 1, 2013

Copyright (C) 2013 Mary Arai et al. This is an open access article distributed under the Creative Commons Attribution License, which permits unrestricted use, distribution, and reproduction in any medium, provided the original work is properly cited.

\begin{abstract}
Full-thickness incisional wounds were made on the dorsal skin of 1-day-old rats to elucidate the mechanism of the fluctuation of the epidermal thickness after the wound closure. The thickness of the epidermis covering the wound reached a peak around $96 \mathrm{~h}$ post-wounding $(\mathrm{PW})$, and became thinner thereafter. The analyses of the cell proliferation and apoptosis at the epidermal wound regions revealed that the rate of TUNEL-positive cells that displays the cells undergoing apoptosis increased as the epidermis became thinner around $120 \mathrm{~h} \mathrm{PW}$. Next, immunohistochemical analyses using antibodies against keratinocyte differentiation marker proteins indicated that the delay or interruption of the spinous to granular transition from 96 to $120 \mathrm{~h} \mathrm{PW}$ might result in the epidermal thickening in the wound region. Third, the region undyed with anti-caspase-14 antibody extended downward in the thickened epidermis by $96 \mathrm{~h} \mathrm{PW}$, and in turn, it became intensely and widely stained with this antibody in the thinning epidermis by $120 \mathrm{~h} \mathrm{PW}$. Taken together, it is likely that the delay and acceleration of the terminal differentiation, including cornification of the epidermal keratinocytes may coordinately cause the fluctuation of the thickness of the epidermis at the wound site in rat neonates.
\end{abstract}

Keywords: Wound Healing; Reepithelialization; Rat; Neonate; Epidermis; Terminal Differentiation; Cornification

\section{Introduction}

Reepithelialization, a part of the process of the wound healing, is essential for organisms to survive. The patterns of reepithelialization are known to differ during the developmental stages [1-6]. First, the wounds in mammalian adult skin are sealed with fibrin clot and then the wound closure is driven by epidermis crawling from the wound margin [7]. Meanwhile, the wounds in the neonatal rat skin are covered rapidly with the extended woundsurrounding epidermis, and the abnormal expression patterns of keratins and cadherins at the wound site have been revealed by immunohistochemical analyses $[6,8]$.

However, the late stages of reepithelialization after the wound closure have not yet been well investigated. In this study, we focused on the phenomenon that, once fullthickness incisional wounds made on the skin of neonatal rats were closed, the thickness of the covering epidermis increased and temporarily overran and, in turn, restored its normal level.

\footnotetext{
"Corresponding author.
}

First, we examined the possible fluctuation of the epidermal cell number at the wound site, and calculated the rate of the cell proliferation as well as that of the cell death detected by anti-BrdU immunostaining and TUNEL, respectively. Second, we analyzed the terminal differentiation of the epidermal keratinocytes. In order to identify the differentiation stage of the wound epidermis after the wound closure, the immunohistochemistry was performed using antibodies of involucrin, profilaggrin/ filaggrin, and loricrin as the epidermal differentiation markers [9-12]. Finally, we examined the distribution of CCAAT/enhancer-binding protein- $\alpha$ (C/EBP- $\alpha$ ) and caspase-14. These two proteins are known to be endogenous factors regulating the terminal differentiation of the epidermal keratinocytes at the early or late stages, respectively [12-20].

The findings in the present study are summarized as follows. The delay or derangement in the terminal differentiation of keratinocyte occurs within the areas from the upper spinous to the granular layer in the thickening epidermis at the wound region. The thinning of the 
wound epidermis may also be associated with the cornification probably accompanied by an enhancement of the cell death and the action of caspase- 14 .

\section{Materials and Methods}

\subsection{Wounding}

Sprague-Dawley rats were anesthetized at 1 day after birth. Two incisional wounds $3 \mathrm{~mm}$ in length were made in the back skin on either side of the dorsal midline with a disposable scalpel (FEATHER). The wound sites were immediately covered with the cover agent Opsite (Smith $\&$ Nephew), and the wounded individuals were returned to the mother rats. The Opsite treatment had no effects on the wound healing except that it avoided unnecessary retardation of healing due to the infection that otherwise occasionally occurred (Koizumi et al., 2004).

\subsection{BrdU Injection}

Two hours before sampling, $10 \mu \mathrm{l} /$ gram body-weight 10 $\mathrm{mM}$ 5-bromo-2'-deoxyuridine (BrdU) were injected into the abdominal cavity of rats.

\subsection{Histology and Immunohistochemistry}

The skin surrounding the wound was cut out at $0,48,72$, 96, 120, or $144 \mathrm{~h} \mathrm{PW}$. Pieces of the skin were fixed with $4 \%$ paraformaldehyde in $\mathrm{Ca}^{2+}, \mathrm{Mg}^{2+}$-free phosphate-buffered saline $[\operatorname{PBS}(-)]$ for $1 \mathrm{~h}$ at room temperature, and embedded in paraffin. Sections ( $4 \mu \mathrm{m}$ thickness) were stained with hematoxylin-eosin (HE) or analyzed immunohistochemically. For immunohistochemistry, deparaffinized sections were pretreated with citric acid buffer (pH 6.0) at $95^{\circ} \mathrm{C}$, and rinsed with $\operatorname{PBS}(-)$. Alternatively, the sections were pretreated with $2 \mathrm{~N} \mathrm{HCl}$, followed by digestion with $0.05 \%$ trypsin at $37^{\circ} \mathrm{C}$. The pretreated sections were incubated with $1 \%$ normal horse serum in $\operatorname{PBS}(-)$ for $20 \mathrm{~min}$, and then reacted with primary antibodies at $4^{\circ} \mathrm{C}$ overnight. They were washed with $\operatorname{PBS}(-)$, then incubated with secondary antibodies for $2 \mathrm{~h}$. Samples were washed with $\operatorname{PBS}(-)$, counterstained with 4',6diamino-2-phenylindole dihydrochloride (DAPI, Polysciences) at $0.1 \mu \mathrm{g} / \mathrm{ml}$, and mounted with Fluoromount (Japan Tanner Corporation). The following primary antibodies were used: mouse anti-cytokeratin 14 monoclonal antibody (mAb) (Chemicon, 1:100); mouse anti-cytokeretin 10/13 mAb (Lab Vision, 1:100); mouse anticytokeratin $6 \mathrm{mAb}$ (Progen, 1:50); rabbit anti-mouse involucrin poriclonal antibody (pAb) (Berkley antibody company, 1:500); rabbit anti-mouse loricrin pAb (abcam, 1:500); rabbit anti-rat profilaggrin/filaggrin pAb (466) (generously supplied by Dr. R. B. Presland, 1:250); and mouse anti-BrdU mAb (Dako Cytomation, 1:100). Alexa fluor 594 goat anti-mouse $\mathrm{IgG}_{1}$ (Molecular Probes,
1:1500); Alexa fluor 488 goat anti-mouse $\operatorname{IgG}_{2 \mathrm{a}}$ (Molecular Probes, 1:500); Alexa fluor 488 goat anti-mouse $\mathrm{IgG}_{1}$ (Molecular Probes, 1:500); and Alexa fluor 488 goat anti-rabbit IgG (Molecular Probes, 1:500) were used as secondary antibodies.

The double staining of loricrin with involucrin and involucrin with filaggrin, and the staining of C/EBP- $\alpha$ and caspase 14 were performed using immunoenzyme technique. Deparaffinized sections were treated with citric acid buffer $(\mathrm{pH} 6.0)$ at $95^{\circ} \mathrm{C}$ or $10 \%$ TritonX-100 in $\operatorname{PBS}(-)$, and endogenous peroxidase was inactivated by $\mathrm{H}_{2} \mathrm{O}_{2}$ before blocking process. After incubation with HRP-conjugated anti-rabbit immunogrobulins (DakoCytomation, 1:100) as the secondary antibody, the samples were reacted with DAB for color reaction. The samples for the double staining were subjected to staining with the next primary antibodies, followed by staining the alkaline phosphatase-conjugated anti-rabbit immunogrobulins (sigma-aldrich, 1:100) as the next secondary antibody. The immunostained sections were finally counterstained with hematoxylin. The following primary antibodies were used: anti-C/EBP- $\alpha$ rabbit pAb (Santa Cruz, $1: 100$ ); and anti-caspase 14 rabbit pAb (IMGENEX, $1: 1000)$.

\subsection{TUNEL}

The TUNEL reaction was performed using in situ cell death detection kit and TMR red (Roche Diagnotics) according to the manufacture's instructions.

\subsection{Numerical Applications of the Rate of BrdU and TUNEL Positive Cells}

The ratios of the numbers of BrdU- or TUNEL-positive cells to those of DAPI positive cells in the wound areas or the intact areas of epidermis were calculated. The epidermal regions between both wound edges and the normal interfollicular epidermal regions more than $5 \mathrm{~mm}$ away from the wound edges were defined as the wound areas and the intact areas of epidermis, respectively, in this study.

\section{Results}

\subsection{Morphological and Immunohistochemical Changes in the Incisional Wound}

The standard technique using a scalpel No. 11 (FEATHER) in this study usually generated the full-thickness incisional wounds $1 \mathrm{~mm}$ in depth, as shown in Figure 1(A) (0 h PW). By 48 h PW, wound closure was completed by the epidermal sheets that crawled from the wound edge and contacted with each other at the wound center (Figure 1(B)). From 72 to $120 \mathrm{~h} \mathrm{PW}$, the epidermis covering the wound was thickened downward the dermis as compared with the normal area of epidermis, and the thick- 


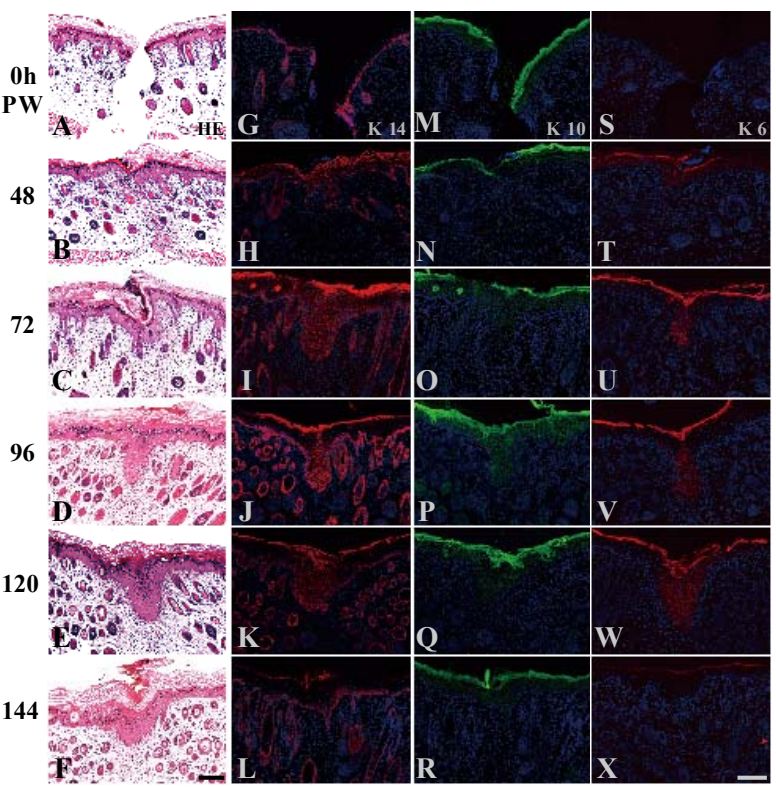

Figure 1. Morphological and immunohistochemical changes in neonatal rat skin wounds during reepithelialization. Serial cross sections were prepared and stained with hematoxylin-eosin ((A)-(F)), and anti-K14 ((G)-(L)), K10 ((M)(R)), or K6 ((S)-(X)) antibodies. At 0 h PW, K14 and K10 keratins were localized at the basal layer (G), and the suprabasal layer $(M)$, respectively. In contrast, K6 keratin was undetectable at 0 h PW (S). Around 48 h PW, wound closure was completed (B). By that time, the distribution of K14-positive cells were expanded vertically throughout the suprabasal layers and stretched horizontally from the wound edge $(\mathrm{H})$; K10-positive cells were absent from the wound-covering areas $(\mathrm{N})$; and $\mathrm{K6}$ keratin became detectable in the suprabasal layers through the wound-covering and the wound-surrounding areas (T). By $72 \mathrm{~h} \mathrm{PW}$ when the wound had been closed, the epidermis was thickened downward the dermis (C). The thickening lasted up to $96 \mathrm{~h}$ PW (D). These extending patterns of K 14 and K 6 were gradually shifted to the normal patterns from the distal region of the wounds from 72 to $120 \mathrm{~h}$ PW ((I)-(K), (U)$(W))$. Conversely K10-positive cells were gradually increased with time in the wounded areas ((O)-(Q)). At $120 \mathrm{~h}$ $P W$, the thickened epidermis was beginning to be thinner $((E),(F))$. The normal localization of these keratins was almost recovered in the wounded areas at $144 \mathrm{~h}$ PW ((L), (R), (X)). Scale bars, $100 \mu \mathrm{m}$; and Counterstained, with DAPI.

ening peaked around $96 \mathrm{~h}$ PW (Figures 1(C)-(E)). At $144 \mathrm{~h} \mathrm{PW}$, the thickened epidermis tended to become thinner (Figure 1(F)), and finally, the wound-covering epidermis almost restored the normal thickness $192 \mathrm{~h} \mathrm{PW}$ (data not shown).

In addition, the immunohistochemical analyses using the epidermal differentiation markers showed that K14 keratin was localized at the basal layer, and the localization of K10 keratin was observed at the suprabasal layer, whereas K6 keratin was not detectable, at $0 \mathrm{~h}$ PW (Figures 1(G), (M), (S)). The localizations of these keratins- positive cells in the wound-covering and the woundsurrounding epidermis fell into disorder within 48 hours after wounding (Figures 1(H), (N), (T)), and gradually recovered the normal patterns from the distal region of wound during reepithelialization (Figures 1(I)-(L), (O)(R), (U)-(X)).

\subsection{The Analyses of the Process in Which the Temporarily Thickened Epidermis Becomes Thinner}

From the above-mentioned histological observations, we noticed that the epidermis was thickened just after wound closure, and thereafter became thinner. Then, we became interested in what was the cause of the fluctuation of the epidermal thickness at the wound areas. To begin with, we speculated that the number of the epidermal cells would change at the wound. Exactly the living cells in the thickened epidermis outnumbered those in the control epidermis, as long as the total numbers of DAPI-positive nuclei were compared (Figure 2(Q)). Therefore, we further analyzed cell proliferation and apoptosis in the wound and intact areas of epidermis to find the answer to the fluctuation of the epidermal cell number.

BrdU-positive cells as the proliferating cells were detected in the basal layer at $0 \mathrm{~h} \mathrm{PW}$ and in the woundcovering epidermis from $48 \mathrm{~h} \mathrm{PW}$ onward, too (Figures 2(A)-(F)). Here, the absolute number of BrdU-positive cells in the epidermal wound regions suggested that the cell proliferation took place during the thickening of the epidermis in the wound region. However, when the ratios of the number of the proliferating cells to the total number of living cells were estimated, the rate in the wound areas of epidermis were almost constant throughout the period tested and, moreover, there was no great difference between these rates in the wound and the intact epidermis (Figures 2(G) and (H)). Consequently, it was likely that the down-regulation of cell proliferation, if any, did not so much contribute to the thinning of the wound-covering epidermis.

Next, we did TUNEL staining to test the possibility that apoptosis is induced in the thickened epidermis as the epidermis became thinner and reduced in cell number. From $0 \mathrm{~h}$ to $96 \mathrm{~h} \mathrm{PW}$, the rates of TUNEL-positive cells in both the wound and intact epidermis were generally similar, though more or less variable (Figures 2(I)-(L), (O), (P)). At $120 \mathrm{~h} \mathrm{PW,} \mathrm{however,} \mathrm{the} \mathrm{rate} \mathrm{of}$ TUNEL-positive cells in the epidermal wound site significantly increased, as compared with that in the intact or $0 \mathrm{~h} \mathrm{PW}$ (Figures 2(M), (O), (P)). The wound region at $144 \mathrm{~h} \mathrm{PW}$ had still a high rate of TUNEL-positive cells (Figures 2(N), (O), (P)). The epidermis in the wound area reached a rate equivalent to that of the normal epidermis at $192 \mathrm{~h} \mathrm{PW}$ (data not shown). It should be noted that TUNEL-positive cells were observed only in the vicinity of the nucleated upper granular layer in both 

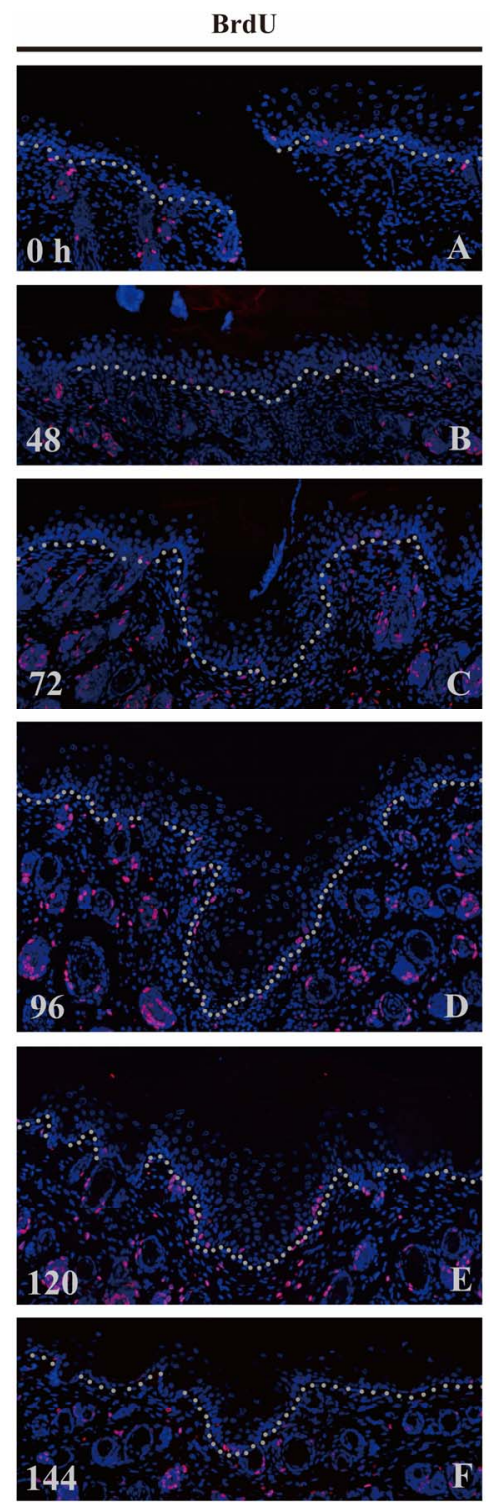
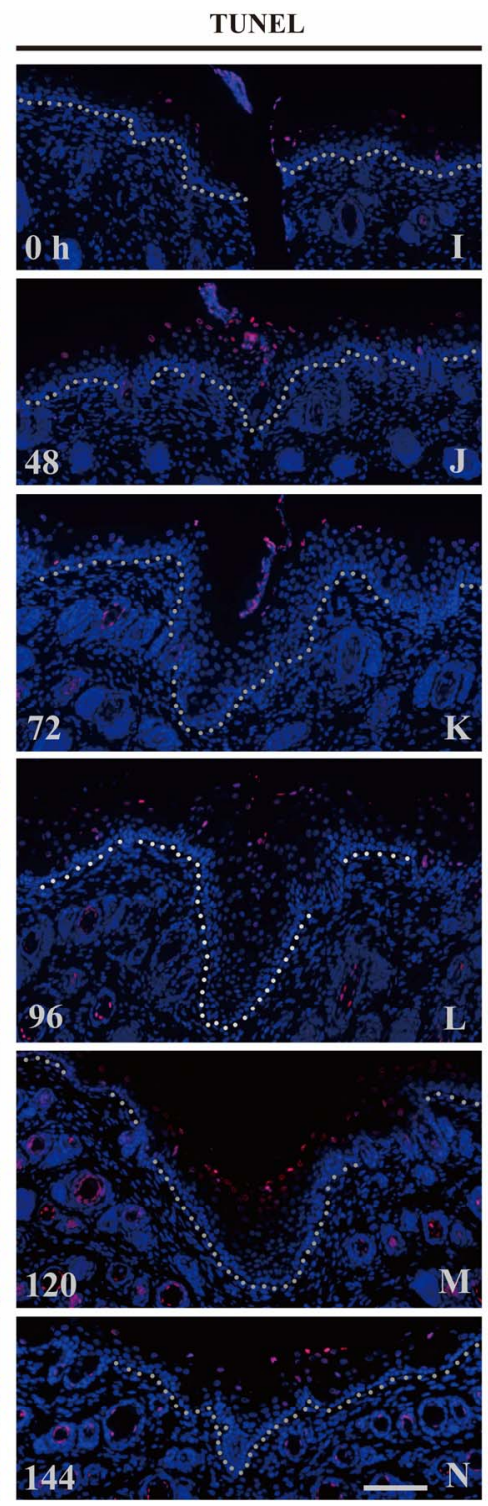
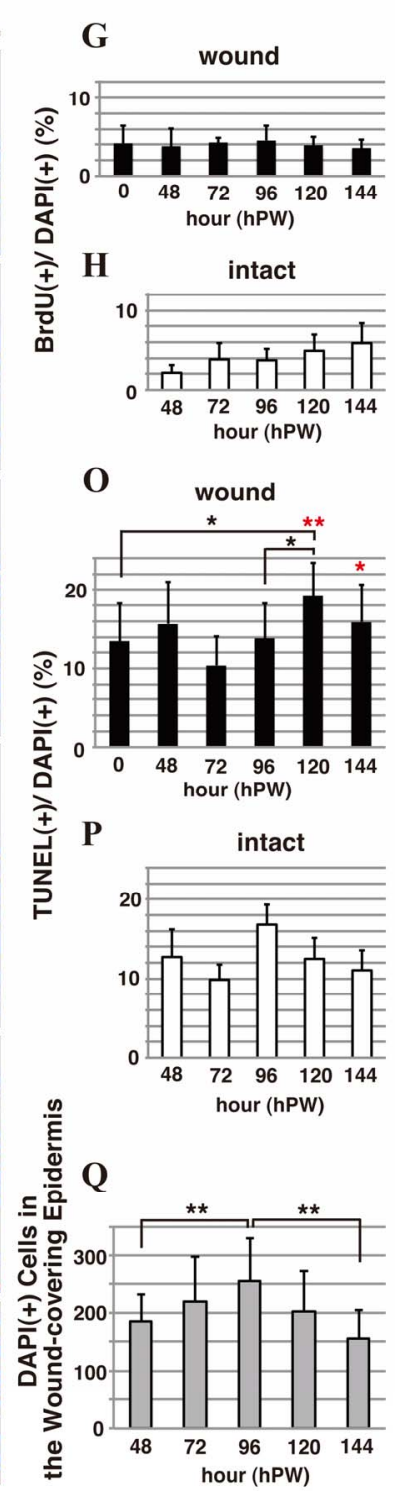

Figure 2. Cell proliferation and apoptosis in the wound and intact areas of epidermis. The rate of the number of "BrdU-positive cells (stained red)", which represents the proliferating cells, to the total number of living cells in the wound

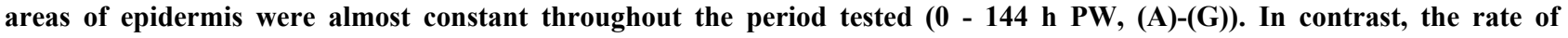
"TUNEL-positive cells (stained red)" that displays the cells undergoing apoptosis increased as the epidermis became thinner (around $120 \mathrm{~h}$ PW), ((I)-(O)). The total numbers of DAPI-positive nuclei in the wound areas of epidermis at 48 - $144 \mathrm{~h}$ PW were counted as the living cells $(\mathrm{Q})$. Scale bar, $100 \mu \mathrm{m}$; counterstain, DAPI; dashed lines, the border between the epidermis and dermis; *, $\mathrm{p}<0.05$; **, $\mathrm{p}<0.01$; and Red asterisks, comparisons of intact values.

wound and intact epidermis.

These results suggested that cornification accompanying cell death is significantly elevated during the thinning of the epidermis at the wound region.

\subsection{The Rates of the Terminal Differentiation May Be Perturbed in the Epidermal Wound Areas}

The epidermal keratinocytes generate diverse differentiation marker proteins during the terminal differentiation.
We examined the localizations of these markers. First, the double immunostaining of loricrin and involucrin was executed during the process of wound healing. In both the wound and normal areas of the neonatal skin at $0 \mathrm{~h}$ PW, loricrin (brown) was expressed at and above the granular layer, whereas involucrin (blue) at and above the upper spinous layer (Figure 3(A)): i.e., there was a clear spatial (and possibly temporal) difference in the start of expression between loricrin and involucrin. At $48 \mathrm{~h}$ PW when epidermis from the wound margin completed wound closure, such normal expression pattern remained 

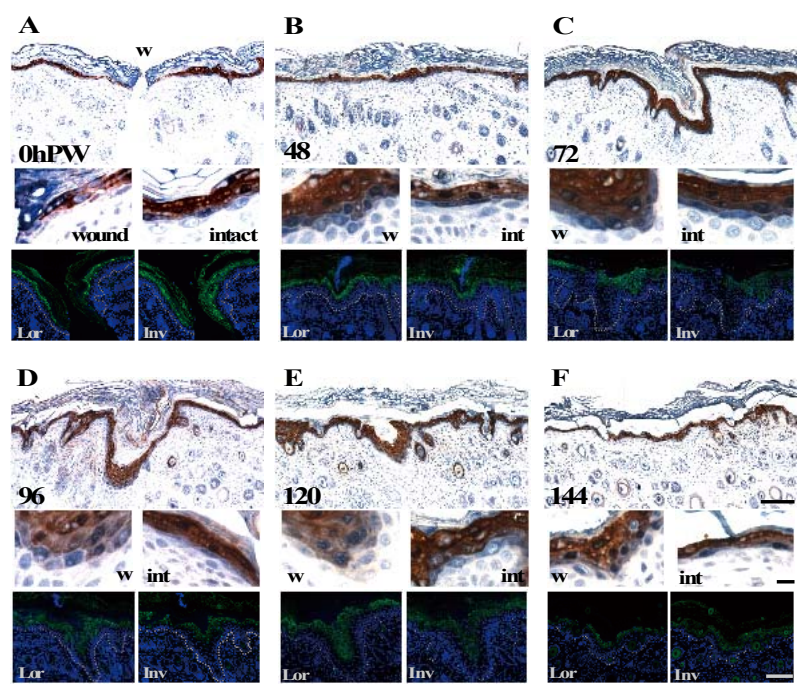

Figure 3. The loricrin-positive lowermost epidermal layer became identical to the involucrin-positive one from the middle of reepithelialization. The upper and middle panels (the magnifications of wound (left) and intact (right) areas) show the expression of anti-loricrin (brown) and involucrin (blue) detected by double staining using the enzyme-labeled antibodies, and the lower panels show these proteins single-stained with fluorescence-labeled antibodies (green) in the adjacent sections. Loricrin (brown) was expressed at and above the granular layer, and involucrin (blue) appeared from the upper spinous layer in the neonatal skin at 0 h PW (A). It should be noted that these two proteins were apt to be stained from the same layer at 96 and $120 \mathrm{~h} P W$ in the epidermal thickening regions ((D) and (E) wound). Scale bars, $100 \mu \mathrm{m}, 10 \mu \mathrm{m}$, and $100 \mu \mathrm{m}$ from above; counterstain, hematoxylin and DAPI; and dashed lines, the border between the epidermis and dermis.

at the wound-covering epidermis (Figure 3(B)). On the contrary, at 96 and $120 \mathrm{~h} \mathrm{PW}$ when the epidermis at the wound areas was thickened, these two proteins were expressed from the identical cell layer in the epidermal thickening regions (Figures 3(D) and (E)), although it remained unclear which protein sifted. Later, the epidermal wound area getting thinner inchmeal recovered the normal expression pattern (144 h PW, Figure 3(F)).

Next, we carried out the double immunostaining of the epidermis of the neonates using the anti-involucrin and anti-profilaggrin/filaggrin antibodies. In both the wound and normal areas at $0 \mathrm{~h} \mathrm{PW}$, the expression of profilaggrin/filaggrin (blue) was observed at the zone lower than involucrin (brown), concretely, at and above the middle spinous cell layer (Figure 4(A)). In contrast, unlike the relationship of expression of loricrin and involucrin, the spatial difference in the expression of involucrin and profilaggrin/filaggrin were maintained in the same way as in the normal areas in the same thickening epidermis specimens. Such an expression pattern remained unchanged by the thinning phase of the wound-covering epidermis (Figures 4(B)-(F)).
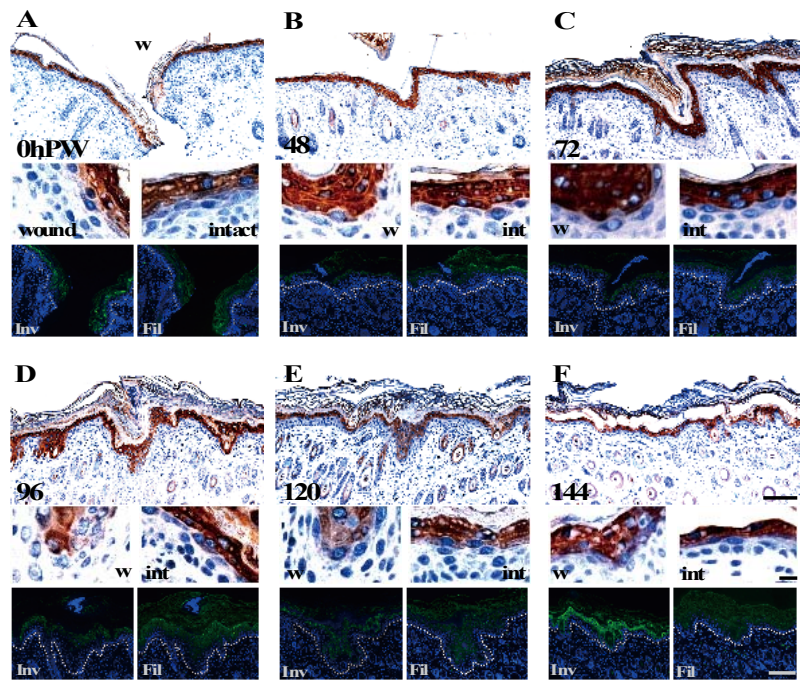

Figure 4. The expression patterns of filaggrin remained unchanged during reepithelialization. The results of double staining of involucrin (brown) and filaggrin (blue) and single staining in the adjacent sections (green) are arranged in the same way as in Figure 3. Unlike the expression of involucrin (brown) that started from upper spinous layer, filaggrin (blue) was expressed at and above the middle spinous layer in the $0 \mathrm{~h}$ PW (A), and maintained this hierarchical relation until $144 \mathrm{~h}$ PW ((B)-(F)). Scale bars, 100 $\mu \mathrm{m}, 10 \mu \mathrm{m}$, and $100 \mu \mathrm{m}$ from above; counterstain, hematoxylin and DAPI; and dashed lines, the border between the epidermis and dermis.

\subsection{The Localizations of Expression of Molecules Participating in the Epidermal Terminal Differentiation Fluctuated during Reepithelialization}

We immunohistochemically examined the expression of C/EBP- $\alpha$ and caspase-14, known to participate in the terminal differentiation of the epidermal keratinocytes at the early and late stages, respectively. At $0 \mathrm{~h} \mathrm{PW}, \mathrm{C} / \mathrm{EBP}-$ $\alpha$ was intensely stained at both the nuclei and the cytoplasm of the cells in the suprabasal layer, while caspase14 at the cytoplasm in the granular layer (Figures 5(A) and $(\mathbf{H})$ ). The staining intensities of both molecules at the leading edge of the epidermis were obviously fallen by $24 \mathrm{~h} \mathrm{PW}$ (Figures 5(B) and (I)). At $48 \mathrm{~h} \mathrm{PW}$, these immunostaining intensities were restored to the normal levels at the wound-covering epidermis. The epidermis at 72 h PW showed a similar tendency (Figures 5(C), (D), (J), (K)). By $96 \mathrm{~h}$ PW when the thickness of the woundcovering epidermis reached the peak, the region intensely stained with anti-caspase-14 was confined to the upper layer at the thickening epidermis, and the unstained region remarkably extended (Figure 5(L)). Subsequently, however, the region intensely stained with anti-caspase14 in turn enlarged downward by $120 \mathrm{~h} \mathrm{PW}$ in the midst of the thinning phase (Figure 5(M)). From 96 to $120 \mathrm{~h}$ $\mathrm{PW}$, the localization of C/EBP- $\alpha$-positive cells was 


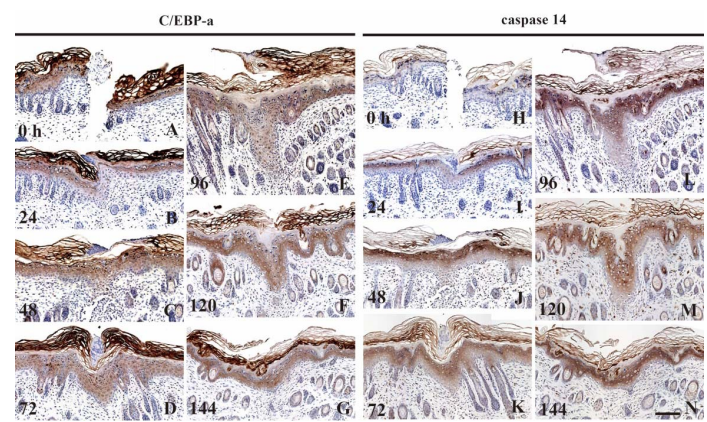

Figure 5. The expression of $\mathrm{C} / \mathrm{EBP}-\alpha$ and caspase-14 in the wound areas. The localization of $\mathrm{C} / \mathrm{EBP}-\alpha$ and caspase-14 was immunohistochemically examined. In the neonatal epidermis at $0 \mathrm{~h}$ PW, C/EBP- $\alpha$ and caspase-14 were distributed in the suprabasal layer (A) and granular layer (H), respectively. At $24 \mathrm{~h} \mathrm{PW}$, both of these molecules were diminished at the wound edge ((B), (I)). After wound closure was completed, these immunostaining intensities were restored to the normal level at the wound-covering epidermis by $48 \mathrm{~h}$ PW ((C), (J)). After that, the localization of C/EBP$\alpha$-positive cells was hardly changed, although the thickness of wound epidermis was varied ((D)-(G)). In contrast, the region unstained with anti-caspase-14 extensively extended downward in the thickened epidermal region by 96 h PW (L). Subsequently, the region intensely stained with anticaspase-14, in turn, became enlarged more downward in the thinning epidermis at $120 \mathrm{~h}$ PW (M). Scale bar, $100 \mu \mathrm{m}$; and counterstained, hematoxylin.

hardly changed (Figures 5(E) and (F)). The epidermis at $144 \mathrm{~h}$ PW showed that both of these two molecules tended to restore the normal level of expression (Figures 5(G) and (N)).

These results suggested that the modulation of the expression of caspase-14 might be responsible for the epidermal thickness.

\section{Discussion}

HE and immunostaining experiments in this study revealed the healing process of the incisional wounds on neonatal rat skin to be outlined as follows (Figure 1). The opened wounds were first closed by the epidermal cells that, keeping the cell-to-cell contact, rapidly extended from the wound margin. Simultaneously, the woundcovering epidermis became thickened. Subsequently, the epidermis at the wound area became thinner up to the normal thickness, accompanying an elevation of the levels of the basal cells and the basement membrane. So, we have further continued morphological analyses of the incisional wounds, with the aim of pursuing the cause of above-stated fluctuation in the epidermal thickness.

\subsection{The Phase of Thinning of Epidermis at the Wound Area and That of the Cell Death in the Upper Epidermis Overlap Each Other}

We estimated the rates of cell proliferation and cell death using anti-BrdU immunostaining and TUNEL staining, respectively, to verify the possible causal relationship between the epidermal cell numbers and the fluctuation of the epidermal thickness in the wound area. The analyses of cell proliferation revealed that there is no clear correlation between the fluctuation of thickness at the wound-covering epidermis and the rate of the proliferating cells (Figures 2(A)-(H)). By contrast, the rate of TUNEL-positive cells rose shortly after peak ( $96 \mathrm{~h} \mathrm{PW}$ ) of the thickness (and the cell number) of the epidermis in the wound area, and reached the peak at $120 \mathrm{~h} \mathrm{PW}$, at which the thinning phase of epidermis was considered to start (Figures 2(M) and (O)). The peak value was 1.4 times as much as that at $96 \mathrm{~h} \mathrm{PW}$. It should be emphasized here that the rates of cell death in the wound areas at 120 and $144 \mathrm{~h} \mathrm{PW}$ were significantly higher than those in the intact areas at 120 and $144 \mathrm{~h} \mathrm{PW}$, respectively (Figures 2(O) and (P)). Thus, the fluctuation of the rate of cell death and that of the thickness of epidermis seemed to coincide with each other. In other words, an elevation of the apoptosis in some cell populations in the upper epidermis may partially contribute to the reduction in the epidermal thickness.

A previous study showed that TUNEL-positive cells were often observed at the granular layer just below the horny layer of epidermis [21]. However, it has recently been reported that apoptosis and the terminal differentiation of keratinocytes are two different independent pathways [22,23]. Meanwhile, there is an article claiming that keratinocytes in the granular layer that express active caspase-14 display TUNEL-positive, being indicative of the physiological role of caspase-14 in relation to the DNA degradation [24]. Namely, an elevation of cell death (TUNEL-positive cells) at the upper part of the granular layer in the midst of thinning of the epidermis may result in an augmentation of cornification.

\subsection{The Derangement Is Generated in the Terminal Differentiation on the Thickness-Fluctuating Epidermis at the Wound Area}

One of the two daughter cells that generates from an epidermal stem cell via the asymmetric cell division is known to have the developmental fate toward the terminal differentiation through which, following several cycles of proliferation, the cell differentiates into spinous, granular and horny cells in order [25]. Such a terminal differentiation process involves not only the shift of keratin expression from K5 and K14 (in the basal layer) to $\mathrm{K} 1$ and $\mathrm{K} 10$ (in the suprabasal layers) but also a sequential switch-on of various differentiation markers such as involucrin, filaggrin, and loricrin in the suprabasal zone [26]. We made the simultaneous comparison of the intraepidermal localization of these differentiation 
marker proteins, using a series of immunostaining experiments, by which we could detect a one-cell-layer difference, if any, between the lowermost localizations of these proteins in the normal neonatal rat skin (Figure 3). Our experimental results showed that, at 96 and $120 \mathrm{~h}$ $\mathrm{PW}$, loricrin and involucrin were expressed above the same cell layer in the thickened epidermis (Figures 3(D) and $(\mathbf{E})$ ). On the other hand, profilaggrin/filaggrin was found to be distributed from a cell layer lower than involucrin. The difference in staining regions lasted until $144 \mathrm{~h} \mathrm{PW}$ (Figure 4). The results obtained from the two sets of analyses of the differentiation markers support the possibility that the stasis or the alteration of the rates in the epidermal terminal differentiation, which occurs probably at the zone from the upper spinous layer to the granular layer, may contribute to the fluctuation of the epidermal thickness at the wound areas.

Taken together, we speculated the post-wound-closure process of the epidermal wound healing, as follows (Figure 6): First, the epidermis at the wound site after the wound closure is thickened by an increase in the number of keratinocytes by an elevation of their proliferation and/or by a delay of differentiation within the

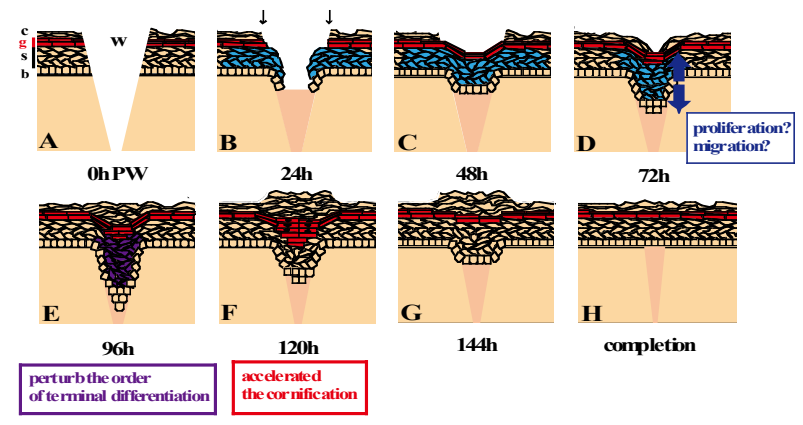

Figure 6. The scheme of re-epithelialization process in the wound of neonatal rat skin. The epidermal stratification at $0 \mathrm{~h}$ PW (A) is arrayed in the same order as that of the normal skin. The granular layer is colored red throughout this figure. The epidermis of the wound edge, which possibly comprises the basal cells and "immature spinous cells" (K14- and K6-positive, but the other differentiation makers-negative; blue) (Koizumi et al. 2004, 2005), migrates into the wound bed by $24 \mathrm{~h} \mathrm{PW}$ (B). Wound closure is completed around $48 \mathrm{~h}$ PW (C). The wound-covering epidermis begins to thicken by $72 \mathrm{~h} \mathrm{PW}$, though the cause is unclear (blue arrows in (D)). Around $96 \mathrm{~h} \mathrm{PW}$, the epidermal thickening region in the wound area becomes thicker, and the terminal differentiation in the suprabasal layers is deranged $((E)$; purple). At 120 h PW, wound-induced thickened epidermis starts to be thinner by some mechanisms possibly involving the accelerated cornification ( $F)$; increase granular cells, red; TUNEL-positive cells, green nuclei). Then, the woundcovering epidermis restores the normal thickness from 144 h PW onward ((G), (H)). b, stratum basale; s, stratum spinosum; $g$, stratum granulosum; $c$, stratum corneum; $w$, wound; and black arrows, the initial position of the wound edge. spinous and granular layers. Next, the epidermal keratinocytes are rapidly cornified by a sudden acceleration of the differentiation to restore the steady state of epidermis. Although more evidence is necessary to establish this line of scheme, another noteworthy fact is the presence of the thick-multilayered horny layers on the thickening epidermis at the wound. This is an indication of the occurrence of transient and active cornification that may couple with the thinning of epidermis at the wound region.

\subsection{A Spatial Expansion of Caspase-14 May Correlates with the Thinning of the Epidermis at the Wound Area}

As the last analysis in this study, we examined the expression of $\mathrm{C} / \mathrm{EBP}-\alpha$ and caspase-14 that are known to closely participate in the terminal differentiation of keratinocytes. C/EBP- $\alpha$ is a transcription factor, acting on the early phase of the terminal differentiation [14,15], whereas caspase-14 a proteolytic enzyme involved in the cornification step $[12,17]$. During the early stage when the epidermal sheets were migrating for the wound closure, C/EBP- $\alpha$ and caspase-14 were absent from the leading edges (Figure 5), fairly consistent with the decrease of K10 expression and the spatial expansion of K14 staining (Figure 1). Following that, at 96 h PW, the pachychromatic region for caspase-14 was confined to the upper layers at the wound epidermis, and the region undyed was widely observed in the lower layers than that (Figure 5(L)). We inferred from these results that, at the thickening epidermis in the wound site, the cornification might be delayed by some down-regulation of the expression of caspase-14. The proportion of the granular layer to the total number of the epidermal cells at wounds might otherwise be reduced by a delay in the terminal differentiation process or activation of cell proliferation. Around the middle of the thinning phase at $120 \mathrm{~h} \mathrm{PW}$, the areas intensely stained with anti-caspase-14 at the wound epidermis were extended more downward (Figure 5(M)). Accordingly, the breakthrough of the terminal differentiation that had been arrested until then may be related to the expansion of expression of caspase-14 or the rapid increase of granular cells there.

\section{Conclusion}

In conclusion, one of the most plausible causes for the fluctuation of the epidermal thickness at the wound areas is considered to be a delay and acceleration of the terminal differentiation, including cornification, in the epidermal keratinocytes. Further analyses from the other viewpoints of cellular migration, intercellular and intracellular signaling, and regeneration of some specific cells, etc. are needed for thorough elucidation of how and why 
the thickness of the wound-covering epidermis fluctuates.

\section{Acknowledgements}

We thank the members of our Morphogenesis Laboratories for their support and helpful discussions in weekly seminars for furthering this study.

\section{REFERENCES}

[1] J. D. Burrington, "Wound Healing in the Fetal Lamb," Journal of Pediatric Surgery, Vol. 6, No. 5, 1971, pp. 523-528. http://dx.doi.org/10.1016/0022-3468(71)90373-3

[2] J. B. Dixon, "Inflammation in the Foetal and Neonatal Rat: the Local Reactions to Skin Burns," The Journal of Pathology and Bacteriology, Vol. 80, No. 1, 1960, pp. 73-82. http://dx.doi.org/10.1002/path.1700800109

[3] S. Ihara, Y. Motobayashi, E. Nagao and A. Kistler, "Ontogenetic Transition of Wound Healing Pattern in Rat Skin Occurring at the Fetal Stage," Development, Vol. 110, No. 3, 1990, pp. 671-680.

[4] M. T. Longaker, D. J. Whitby, N. S. Adzick, T. M. Crombleholme, J. C. Langer, B. W. Duncan, S. M. Bradley, R. Stern, M. W. Ferguson and M. R. Harrison, "Studies in Fetal Wound Healing, VI. Second and Early Third Trimester Fetal Wounds Demonstrate Rapid Collagen Deposition without Scar Formation," Journal of Pediatric Surgery, Vol. 25, No. 1, 1990, pp. 63-68, Discussion 8-9.

[5] P. Martin, "Mechanisms of Wound Healing in the Embryo and Fetus," Current Topics in Developmental Biology, Vol. 32, 1996, pp. 175-203. http://dx.doi.org/10.1016/S0070-2153(08)60428-7

[6] M. Koizumi, T. Matsuzaki and S. Ihara, "The Subsets of Keratinocytes Responsible for Covering Open Wounds in Neonatal Rat Skin," Cell and Tissue Research, Vol. 315, No. 2, 2004, pp. 187-195. http://dx.doi.org/10.1007/s00441-003-0823-0

[7] P. Martin and S. M. Parkhurst, "Parallels between Tissue Repair and Embryo Morphogenesis," Development, Vol. 131, No. 13, 2004, pp. 3021-3034. http://dx.doi.org/10.1242/dev.01253

[8] M. Koizumi, T. Matsuzaki and S. Ihara, "Expression of P-Cadherin Distinct from That of E-Cadherin in Re-Epithelialization in Neonatal Rat Skin," Development, Growth \& Differentiation, Vol. 47, No. 2, 2005, pp. 75-85. http://dx.doi.org/10.1111/j.1440-169x.2004.00784.x

[9] C. Byrne, M. Tainsky and E. Fuchs, "Programming Gene Expression in Developing Epidermis," Development, Vol. 120, No. 9, 1994, pp. 2369-2383.

[10] E. R. Li, D. M. Owens, P. Djian and F. M. Watt, "Expression of Involucrin in Normal, Hyperproliferative and Neoplastic Mouse Keratinocytes," Experimental Dermatology, Vol. 9, No. 6, 2000, pp. 431-438. http://dx.doi.org/10.1034/j.1600-0625.2000.009006431.x

[11] R. B. Presland, M. K. Kuechle, S. P. Lewis, P. Fleckman and B. A. Dale, "Regulated Expression of Human Filaggrin in Keratinocytes Results in Cytoskeletal Disruption, Loss of Cell-Cell Adhesion, and Cell Cycle Arrest," Experimental Cell Research, Vol. 270, No. 2, 2001, pp. 199213. http://dx.doi.org/10.1006/excr.2001.5348

[12] G. Denecker, P. Ovaere, P. Vandenabeele and W. Declercq, "Caspase-14 Reveals Its Secrets," The Journal of Cell Biology, Vol. 180, No. 3, 2008, pp. 451-458. http://dx.doi.org/10.1083/jcb.200709098

[13] P. F. Jhonson, "Molecular Stop Signs: Regulation of CellCycle Arrest by C/EBP Transcription Factors," Journal of Cell Science, Vol. 118, 2005, pp. 2545-2555. http://dx.doi.org/10.1242/jcs.02459

[14] E. V. Maytin, J. C. Lin, R. Krishnamurthy, N. Batchvarova, D. Ron, P. J. Mitchell and J. F. Habener, "Keratin 10 Gene Expression during Differentiation of Mouse Epidermis Requires Transcription Factors C/EBP and AP-2," Developmental Biology, Vol. 216, No. 1, 1999, pp. 164-181. http://dx.doi.org/10.1006/dbio.1999.9460

[15] H. S. Oh and R. C. Smart, "Expression of CCAAT/Enhancer Binding Proteins (C/EBP) Is Associated with Squamous Differentiation in Epidermis and Isolated Primary Keratinocytes and Is Altered in Skin Neoplasms," The Journal of Investigative Dermatology, Vol. 110, No. 6, 1998, pp. 939-945. http://dx.doi.org/10.1046/j.1523-1747.1998.00199.x

[16] M. Van de Craen, G. Van Loo, S. Pype, W. Van Criekinge, I. Van den brande, F. Molemans, W. Fiers, W. Declercq and P. Vandenabeele, "Identification of a New Caspase Homologue: Caspase-14," Cell Death and Differentiation, Vol. 5, No. 10, 1998, pp. 838-846. http://dx.doi.org/10.1038/sj.cdd.4400444

[17] S. Lippens, M. Kockx, M. Knaapen, L. Mortier, R. Polakowska, A. Verheyen, M. Garmyn, A. Zwijsen, P. Formstecher, D. Huylebroeck, P. Vandenabeele and W. Declercq, "Epidermal Differentiation Does Not Involve the Pro-Apoptotic Executioner Caspases, but Is Associated with Caspase-14 Induction and Processing," Cell Death and Differentiation, Vol. 7, No. 12, 2000, pp. 1218-1224. http://dx.doi.org/10.1038/sj.cdd.4400785

[18] L. Alibardi, E. Tschachler and L. Eckhart, "Distribution of Caspase-14 in Epidermis and Hair Follicles Is Evolutionarily Conserved among Mammals," The Anatomical Record Part A: Discoveries in Molecular, Cellular, and Evolutionary Biology, Vol. 286, No. 2, 2005, pp. 962973. http://dx.doi.org/10.1002/ar.a.20234

[19] E. Hoste, P. Kemperman, M. Devos, G. Denecker, S. Kezic, N. Yau, B. Gilbert, S. Lippens, P. De Groote, R. Roelandt, P. Van Damme, K. Gevaert, R. B. Presland, H. Takahara, G. Puppels, P. Caspers, P. Vandenabeele and W. Declercq, "Caspase-14 Is Required for Filaggrin Degradation to Natural Moisturizing Factors in the Skin," The Journal of Investigative Dermatology, Vol. 131, No. 11, 2011, pp. 2233-2241. http://dx.doi.org/10.1038/jid.2011.153

[20] L. Eckhart and E. Tschachler, "Cuts by Caspase-14 Control the Proteolysis of Filaggrin," The Journal of Investigative Dermatology, Vol. 131, No. 11, 2011, pp. 21732175. http://dx.doi.org/10.1038/jid.2011.282

[21] C. A. McCall and J. J. Cohen, "Programmed Cell Death 
in Terminally Differentiating Keratinocytes: Role of Endogenous Endonuclease," The Journal of Investigative Dermatology, Vol. 97, No. 1, 1991, pp. 111-114. http://dx.doi.org/10.1111/1523-1747.ep12478519

[22] M. Rendl, J. Ban, P. Mrass, C. Mayer, B. Lengauer, L. Eckhart, W. Declercq and E. Tschachler, "Caspase-14 Expression by Epidermal Keratinocytes is Regulated by Retinoids in a Differentiation-Associated Manner," The Journal of Investigative Dermatology, Vol. 119, No. 5, 2002, pp. 1150-1155. http://dx.doi.org/10.1046/j.1523-1747.2002.19532.x

[23] S. Lippense, G. Denecker, P. Ovaere, P. Vandenabeele and W. Declercq, "Death Penalty for Keratinocytes: Apoptosis versus Cornification," Cell Death and Differentiation, Vol. 12, Suppl. 2, 2005, pp. 1497-1508.

http://dx.doi.org/10.1038/sj.cdd.4401722
[24] T. Hibino, E. Fujita, Y. Tsuji, J. Nakanishi, H. Iwaki, C. Katagiri and T. Momoi, "Purification and Characterization of Active Caspase-14 from Human Epidermis and Development of the Cleavage Site-Directed Antibody," Journal of Cellular Biochemistry, Vol. 109, No. 3, 2010, pp. 487-497.

[25] E. Fuchs, "Skin Stem Cells: Rising to the Surface," The Journal Cell Biology, Vol. 180, No. 2, 2008, pp. 273-284. http://dx.doi.org/10.1083/jcb.200708185

[26] H. Tseng and H. Green, "Association of Basonuclin with Ability of Keratinocytes to Multiply and with Absence of Terminal Differentiation," The Journal Cell Biology, Vol. 126, No. 2, 1994, pp. 495-506.

http://dx.doi.org/10.1083/jcb.126.2.495 